\title{
Inheritance of seed size by hybrid populations of pea $\left(F_{1}, F_{2}\right)$
}

\author{
Firzinat Davletov ${ }^{1}$, Karina Gainullina, ${ }^{1,2, *}$, and Fidan Safin $^{3}$ \\ ${ }^{1}$ Bashkir Research Institute of Agriculture - Subdivision of the Ufa Federal Research Centre of the Russian Academy of Sciences, \\ 450059 Ufa, Russia \\ ${ }^{2}$ Insitute of Biochemistry and Genetics - Subdivision of the Ufa Federal Research Centre of the Russian Academy of Sciences, 450054 \\ Ufa, Russia \\ ${ }^{3}$ Educational and Research Center of the Bashkir State Agrarian University, Ufa, Russia
}

\begin{abstract}
Pea (Pisum sativum L.) is one of the ancient and valuable high-protein leguminous cultures in the world. Breeding of new high-yielding cultivars is the main reserve to increase production of pea seeds. At the present time, intraspecific hybridization has a great importance in selection of new cultivars of pea. However, consistent patterns of inheritance of a number of economically valuable traits by hybrids are still insufficiently investigated. The objective of this research work was to study inheritance of seed size (1000kernel weight) by pea hybrids of the first and second filial generations $\left(\mathrm{F}_{1}, \mathrm{~F}_{2}\right)$. The crossing and backcrossing (reciprocal crossing) were conducted. In our experiments, the first filial generation hybrids $\left(\mathrm{F}_{1}\right)$ had a lower 1000-kernel weight than the large-seeded parental cultivars. Herewith the large-seeded genotype of the female parental cultivar had more influence on displaying of this trait in hybrids than of the male parental cultivar. In the second filial generation hybrids $\left(\mathrm{F}_{2}\right)$ showed intermediate inheritance of seed size. The results of our experiments attest high efficiency of seed size selection in segregating generations of hybrids, obtained from crosses between cultivars carrying genes of seed size.
\end{abstract}

\section{Introduction}

Pea (Pisum sativum L.) is widely cultivated all over the world. Pea has a great significance: it is used as food, feed and green manure crop. Pulse crops are very important in fixing atmospheric nitrogen thanks to a symbiotic relationship with root nodule bacterium [1-3].

Such pulse crops as pea, chickpea, soybean, lupine are cultivated in the Republic of Bashkortostan. Over the last years in the republic planting acreage of pea amounted to 42-67 thousands hectares. Edaphoclimatic conditions of the PreUral steppe of Bashkortostan allow obtaining sufficiently heavy grain yield of pea [4-6].

In increasing the grain yield of pea significant role belongs to selection and seed growing of new cultivars. Currently, the great importance in selection of new cultivars has intraspecific hybridization along with the use of interspecific hybridization, method of culture of cells, tissues and organs, experimental polyploidy, physical, and chemical mutagenesis $[3,7,8]$.

The creation of high-yield high-tech pea cultivars adaptive to local environment conditions using this method meets a number of difficulties [2,9]. First of all, it is due to the insufficient study of issues related to clarification of the laws of inheritance of a number of economically valuable traits by hybrids, as well as clarification of the degree of influence of the genotype of parental cultivars on the development of these traits in hybrids $[3,5,10]$. In this article, the results of investigation of some issues of this problem are presented.

\section{Materials and methods}

The study was conducted on the experimental fields of Bashkir Research Institute of Agriculture, Laboratory of selection and seed-growing of pulse crops in 2017-2018.

To study of the character of inheritance of seed size we investigated 5 cultivars of pea: Shihan, Melkosemyannyi 2, Chishminskii 75, Chishminskii 80, and Chishminskii 95.

Small-seeded cultivar Melkosemyannyi 2 was used as pollinator in crosses with four pea cultivars Shihan, Chishminskii 75, Chishminskii 80, and Chishminskii 95. Back-crosses were also carried out.

Sowing the seeds of the first and second pea hybrid of the filial generations was carried out with a selection seeder SKS-6-10. A preceding crop in our experiments was winter rye. Agrotechnics was the one generally accepted for the zone. The feeding area of plants was $20 \times 5 \mathrm{~cm}$. The size of the breeding plots was determined by the availability of seeds. Next to the hybrids were planted the parental cultivars.

The study of inheritance of seed size was carried out on the hybrids of the first and second filial generations $\left(\mathrm{F}_{1}, \mathrm{~F}_{2}\right)$. Trial sheaves of each hybrid combination were selected for analysis. The weight of each kernel was determined in the laboratory. Based on the data obtained from this study, the seeds were grouped into the following classes:

I. Large (1000-kernel weight ranged from 280 to $300 \mathrm{~g}$ ).

II. Semi-large (1000-kernel weight ranged from 250 to $279 \mathrm{~g})$.

* Corresponding author: karina28021985@yandex.ru 
III. Medium (1000-kernel weight ranged from 160 to $249 \mathrm{~g})$.

IV. Semi-small (1000-kernel weight ranged from 130 to $159 \mathrm{~g})$.

V. Small (1000-kernel weight ranged from 90 to $129 \mathrm{~g}$ ).

The standard deviation $(\sigma)$, the coefficient of variation $\left(\mathrm{V}_{\mathrm{c}}, \%\right)$, the coefficient of heritability $\left(\mathrm{H}^{2}\right)$, the degree of dominance $\left(h_{p}\right)$ were estimated. Statistical analysis was conducted in accordance with the methods of field experience suggested by B.A. Dospehov [11] in Microsoft Office Excel 2010 using Statistica 7.0 program.

\section{Results and discussion}

Information about the inheritance of seed size is very deficient [12, 13]. Crossing large-seeded and smallseeded cultivars, Tschermak (1912) observed the intermediate inheritance of the trait in $F_{1}$ generation, and there was a large variety of values of the feature in $F_{2}$ generation. The ratio of the number of small type of seeds to the number of other types of seeds was 1:264 and it was close to $1: 255$, corresponding to the tetrahybrid segregation. Tschermak drew conclusion that the small-seeded sample which he had used in the crosses carried 4 recessive genes of seed size, which he denominated as $a, b, c, d$, while large-seeded sample had dominant alleles - A, B, $C, D$ [14-16].

Wellensiek (1925) replaced these symbols, which has already been used to refer to other genes, with $S g_{1}, S g_{2}$, $\mathrm{Sg}_{3}, \mathrm{Sg}_{4}$. Afterwards these symbols were changed by Yarnell (1964) to $S_{1}, S_{2}, S_{3}, S_{4}[2,17]$.

Lamprecht (1957) received a large-seeded mutant having recessive nature. He denominated the gene that increasing seed size as the symbol ma [18, 19]. Kaznowski (1926) assumed the existence of polymeric genes of kernel length $\mathrm{Lo}, \mathrm{Lo}_{1}, \mathrm{Lo}_{2}, \mathrm{Lo}_{3}$, each of which increased the diameter of the cotyledon by $0.5 \mathrm{~mm}$ [17].

However, this hypothesis had not found material confirmation; besides seed weight is determined not only by the diameter of the seed, but also its consistency and shape. Therefore, in modern literature the genes of seed length suggested by Kaznowski are not usually given.

V. V. Hangil'din and V. H. Hangil'din (1969, 1970) studying the inheritance of seed size used Sewall Wright formula to calculate the minimal number of non-allelic genes determining the differences between cultivars [6]. According to the results of the dispersion analysis of the trait in 10 hybrids between cultivars with different seed sizes it was found that the large-seeded cultivars differ from the small-seeded cultivar Melkosemyannyi 2 in the presence of two dominant alleles of genes.

Cultivar Melkosemyannyi 2 (1000-kernel weight ranged from 80 to $110 \mathrm{~g}$ ) has all the recessive genes of seed size in its genotype. Large-seeded cultivars have 4 or 5 dominant genes of seed size. Seed size in a great measure depends on the genotype of the cultivar and growing conditions [8].

In the literature sources, many researchers note that hybrids of the intermediate type approach the parental cultivars with a more developed trait generate when crossing large-seeded and small-seeded pea cultivars. The trait showing intermediate inheritance in the first filial generation hybrids, gives diversity in the second filial generation hybrids, in which plants with intermediate phenotypes represent a larger fraction $[8,20]$.

In our investigations, the first filial generation hybrids, which were received from crossing and backcrossing (reciprocal crossing) of the cultivars, considerably differing on 1000-kernel weight, had the values of 1000-kernel weight in range of the values of 1000-kernel weight of the parental cultivars. Herewith the $\mathrm{F}_{1}$ hybrids had the values of 1000 -kernel weight approaching the large-seeded parental cultivar, but at the same time, these values were somewhat less than the value of 1000-kernel weight of the large-seeded parental cultivar.

For example, the $F_{1}$ hybrid, whose female parental cultivar were large-seeded plant, had the value of 1000kernel weight, which were $15.4 \%$ less than the value of 1000-kernel weight of the female parental cultivar. The $\mathrm{F}_{1}$ hybrid, whose male parental cultivar were largeseeded plant, had the value of 1000-kernel weight, which were $19.8 \%$ less than the value of 1000-kernel weight of the male parental cultivar (Table 1).

Table 1. 1000-kernel weight in pea $F_{1}$ hybrids and their parental cultivars $(2017$ г.).

\begin{tabular}{|c|c|c|c|c|c|}
\hline \multirow[t]{2}{*}{$\begin{array}{c}\text { Number } \\
\text { of } \\
\text { hybrids, } \\
\text { pes }\end{array}$} & \multicolumn{3}{|c|}{ 1000-kernel weight } & \multicolumn{2}{|c|}{$\begin{array}{l}\text { Deviation of } \\
\text { 1000-kernel } \\
\text { weight in a } \\
\text { hybrid in relation } \\
\text { to the superior } \\
\text { parental cultivar }\end{array}$} \\
\hline & $\begin{array}{c}\text { female } \\
\text { parental } \\
\text { cultivar, } \\
\mathrm{g}\end{array}$ & $\begin{array}{c}F_{1} \\
\text { hybri } \\
d, g\end{array}$ & $\begin{array}{c}\text { male } \\
\text { parental } \\
\text { cultivar, } \\
\mathrm{g} \\
\end{array}$ & $\begin{array}{c}\text { total } \\
\text { value } \\
\pm \mathrm{g}\end{array}$ & $\begin{array}{c}\text { relative } \\
\text { value, } \\
\pm \%\end{array}$ \\
\hline \multicolumn{6}{|c|}{ Crossing } \\
\hline 4 & $253 \pm 5.0$ & $\begin{array}{c}214 \pm \\
3.8 \\
\end{array}$ & $105 \pm 2.8$ & -39 & -15.4 \\
\hline \multicolumn{6}{|c|}{ Back-crossing } \\
\hline 4 & $105 \pm 2.3$ & $\begin{array}{c}203 \pm \\
3.5\end{array}$ & $253 \pm 5.0$ & -50 & -19.8 \\
\hline
\end{tabular}

From the results of investigation it will be obvious that the large-seeded parental genotype had more influence on the value of 1000-kernel weight of the hybrid independently if it was selected as a male or female parental cultivar. However, it should be noted that in our experiments the large-seeded parental genotype had more influence on the value of 1000-kernel weight of the hybrid if it have been used as a female parental cultivar.

In our investigation the $\mathrm{F}_{2}$ hybrids had the higher average values of 1000-kernel weight relative to the $F_{1}$ hybrids (Table 2).

Thus, the data obtained from our study confirm the opinion of most of the authors about the intermediate type of the inheritance of seed size in the second filial generation hybrids (Figure 1). 
Table 2. Distribution of the frequency of seed size of the $\mathrm{F}_{2}$ hybrids and parental cultivars (2018).

\begin{tabular}{|c|c|c|c|c|c|c|}
\hline \multirow{2}{*}{ Cultivar and hybrid } & \multicolumn{5}{|c|}{ Number of kernels (pcs) belonging to the size class } & \multirow{2}{*}{$\begin{array}{c}\text { 1000-kernel } \\
\text { weight, g }\end{array}$} \\
\hline & I & II & III & IV & $\mathrm{V}$ & \\
\hline \multicolumn{7}{|c|}{ Crossing } \\
\hline Shihan & 352 & 605 & 43 & 0 & 0 & $270 \pm 14.6$ \\
\hline Shihan $\times$ Melkosemyannyi 2 & 67 & 256 & 370 & 243 & 64 & $206 \pm 7.8$ \\
\hline Melkosemyannyi 2 & 0 & 0 & 9 & 840 & 151 & $110 \pm 8.6$ \\
\hline Chishminskii 75 & 0 & 89 & 859 & 52 & 0 & $220 \pm 9.0$ \\
\hline Chishminskii $75 \times$ Melkosemyannyi 2 & 0 & 8 & 240 & 504 & 248 & $180 \pm 3.8$ \\
\hline Melkosemyannyi 2 & 0 & 0 & 9 & 840 & 151 & $110 \pm 8.6$ \\
\hline Chishminskii 80 & 105 & 599 & 296 & 0 & 0 & $256 \pm 10.0$ \\
\hline Chishminskii $80 \times$ Melkosemyannyi 2 & 57 & 260 & 470 & 182 & 31 & $206 \pm 7.8$ \\
\hline Melkosemyannyi 2 & 0 & 0 & 9 & 840 & 151 & $110 \pm 8.6$ \\
\hline Chishminskii 95 & 250 & 602 & 148 & 0 & 0 & $263 \pm 10.0$ \\
\hline Chishminskii $95 \times$ Melkosemyannyi 2 & 63 & 250 & 375 & 250 & 62 & $206 \pm 8.0$ \\
\hline Melkosemyannyi 2 & 0 & 0 & 9 & 840 & 151 & $110 \pm 8.6$ \\
\hline \multicolumn{7}{|c|}{ Back-crossing } \\
\hline Melkosemyannyi 2 & 0 & 0 & 9 & 840 & 151 & $110 \pm 8.6$ \\
\hline Melkosemyannyi $2 \times$ Shihan & 60 & 260 & 373 & 233 & 74 & $201 \pm 9.4$ \\
\hline Shihan & 352 & 605 & 43 & 0 & 0 & $270 \pm 14.6$ \\
\hline Melkosemyannyi 2 & 0 & 0 & 9 & 840 & 151 & $110 \pm 8.6$ \\
\hline Melkosemyannyi $2 \times$ Chishminskii 75 & 0 & 13 & 234 & 491 & 262 & $173 \pm 7.8$ \\
\hline Chishminskii 75 & 0 & 89 & 859 & 52 & 0 & $220 \pm 9.0$ \\
\hline Melkosemyannyi 2 & 0 & 0 & 9 & 840 & 151 & $110 \pm 8.6$ \\
\hline Melkosemyannyi $2 \times$ Chishminskii 80 & 70 & 245 & 459 & 192 & 34 & $211 \pm 9.0$ \\
\hline Chishminskii 80 & 105 & 599 & 296 & 0 & 0 & $256 \pm 10.0$ \\
\hline Melkosemyannyi 2 & 0 & 0 & 9 & 840 & 151 & $110 \pm 8.6$ \\
\hline Melkosemyannyi $2 \times$ Chishminskii 95 & 72 & 266 & 361 & 255 & 46 & $217 \pm 9.8$ \\
\hline Chishminskii 95 & 250 & 602 & 148 & 0 & 0 & $263 \pm 10.0$ \\
\hline
\end{tabular}

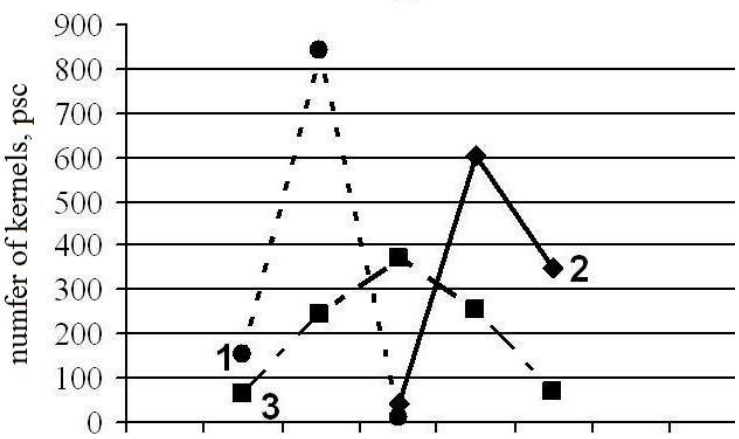

$\begin{array}{lllllll}0 & 90 & 130 & 160 & 250 & 280 & 300\end{array}$

1000-kernel weight, g

B

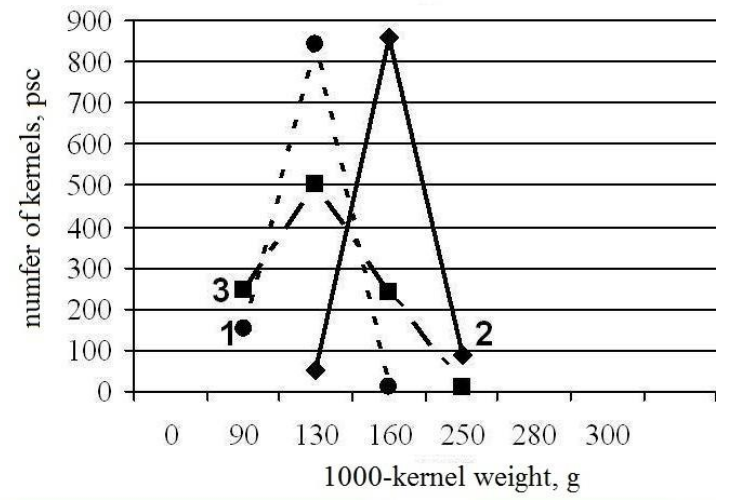

C

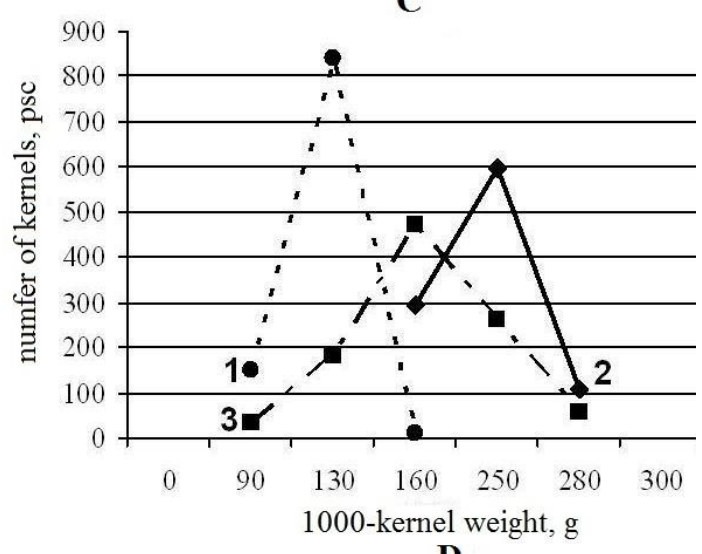

D

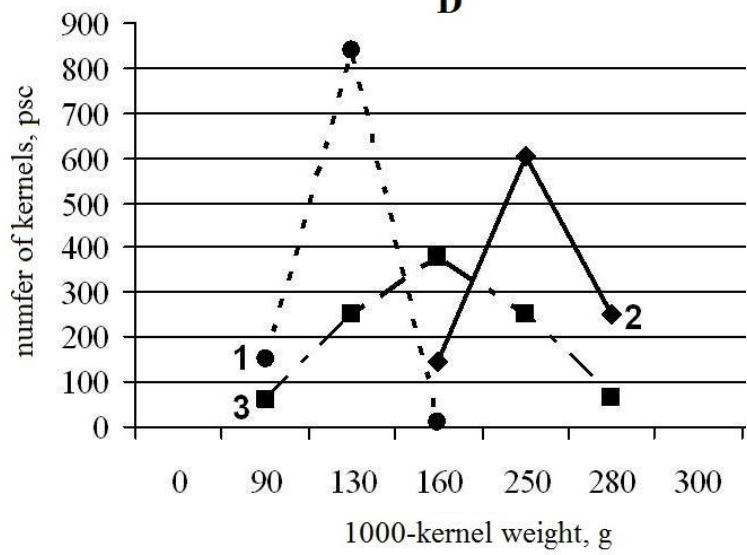

Fig. 1. Distribution of the frequency of $1000-$ kernel weight of the $F_{2}$ hybrids and parental cultivars: A - Shihan (1), Melkosemyannyi 2 (2), Shihan $\times$ Melkosemyannyi 2 (3), B - Chishminskii 75 (1), Melkosemyannyi 2 (2), Chishminskii $75 \times$ Melkosemyannyi 2 (3), C - Chishminskii 80 (1), Melkosemyannyi 2 (2), Chishminskii $80 \times$ Melkosemyannyi 2 (3), D - Chishminskii 95 (1), Melkosemyannyi 2 (2), Chishminskii $95 \times$ Melkosemyannyi 2 (3). 
In our experiments, the coefficient of variation $\mathrm{V}_{\mathrm{c}}$ ranged from 24.3 to $33.3 \%$ in different hybrid populations of the second filial generation, while in the parental cultivars it was equal to $6.5-12.3 \%$. This is due to the fact that the influence of environmental condition was added to the segregation of genotypes. The share of genotypic variability was from 87 to $95 \%$. In the second filial generation we observed incomplete dominance of seed size: the degree of dominance was equal to $0.20-0.32$.

Thus, crossing large-seed cultivars Shihan, Chishminskii 80, Chishminskii 95 and cultivar Melkosemyannyi 2, we observed the intermediate inheritance of seed size in $\mathrm{F}_{1}$ generation due to the lack of dominance of the gene of this trait, and in $F_{2}$ generation we almost failed to obtain desirable hybrids with small seeds, because the frequency of segregation of hybrids, which have 4 or 5 recessive genes, was very low and equaled to $3.1-6.4 \%$. After crossing mediumseeded cultivar Chishminskii 75 and cultivar Melkosemyannyi 2, we detected a large number of small-seeded hybrids.

Following the analysis of this hybrid population we selected 8 semi-large-seeded plants, 240 medium-seeded plants, 504 semi-small-seeded plants, and 248 smallseeded plants. The frequency of segregation of semismall-seeded and small-seeded hybrids was respectively equaled to $50.4 \%$ and $24.8 \%$.

Back-crossing $\mathrm{F}_{2}$ hybrids had intermediate value of 1000-kernel weight with respect to the parental cultivars, approaching the large-seeded parental cultivar and not significantly differing from $\mathrm{F}_{2}$ hybrids, which were received from crossing.

Determination of the coefficient of heritability and trait-specific coefficient of variation in the second filial generation makes it possible to predict the high efficiency of seed size selection in segregating hybrid populations obtained from the crossing of cultivars carrying the genes of seed size.

It is also possible to obtain from the hybrid populations some desirable non-segregating genotypes, which can be further used in selection.

\section{Conclusion}

The results of our experiments agree with literature data and attest high efficiency of seed size selection in segregating generations of hybrids, obtained from crosses between cultivars carrying the genes of seed size. A desirable non-segregating genotypes selected from hybrid populations, can be used further in breeding as donors of large-seeded and small-seeded trait.

\section{Acknowledgments}

The work was carried out within the framework of State Assignment of Ministry of Science and Higher
Education of the Russian Federation AAAA-A19119021190011-0.

\section{References}

1. P.H. Graham, C.P. Vance, Plant Physiol. 131, 872-877 (2003) DOI: 10.1104/pp.017004

2. N. Tayeh, G. Aubert, M.L. Pilet-Nayel, I. LejeuneHénaut, T.D. Warkentin, J. Burstin, Front. Plant Sci. 6, 1037 (2015) DOI: 10.3389/fpls.2015.01037

3. P. Smýkal, G. Aubert, J. Burstin et al., Agronomy 2, 74-115 (2012) DOI: 10.3390/agronomy 2020074

4. F.A. Davletov, K.P. Gajnullina, Agrar. Bull. of the Urals 4, 5-6 (2011)

5. F.A. Davletov, K.P. Gajnullina, Vestnik BSAU 26, 10-13 (2013)

6. V.H. Hangil'din, V.V. Hangil'din, Proc. of the Bashkir Res. Instit. of Agricult. 3, 40-61 (1969)

7. G.V. Gulyaev, A.P. Dubinin, Selection and seed growing of field crops with the basics of genetics (Kolos, Moscow, 1980)

8. V.V. Hvostova, Genetics and selection of pea (Nauka, Novosibirsk, 1975)

9. J. Burstin, P. Salloignon, M. Chabert-Martinello et al., BMC Genomics 16, 105 (2015) DOI: 10.1186/s12864-015-1266-1

10. A.K. Parihar, G.P. Dixit, D. Singh, J. Genet., 95, 947-956 (2016) DOI: 10.1007/s12041-0160722-2

11. B.A. Dospekhov, Methods of field experiment (Al'yans, Moscow, 2011)

12. G. Wenzel, H. Lörz, Molecular marker systems in plant breeding and crop improvement (SpringerVerlag, Berlin, 2005)

13. D. Wilson, A. Russell, J. McCallum et al., Crop Sci. 45, 1336-1344 (2005) DOI: 10.2135/cropsci2004.0436

14. M. Simunek, U. Hossfeld, V. Wissemann, Plant Biol. 13, 835-841 (2011) DOI: 10.1111/j.14388677.2011.00491.x

15. M. Simunek, U. Hossfeld, O. Breidbach, Theory Biosci. 131, 243-252 (2012) DOI: 10.1007/s12064012-0158-z

16. M. Simunek, M. Mielewczik, G.S. Levit, U. Hossfeld, Theory Biosci. 136, 59-67 (2017) DOI: 10.1007/s12064-016-0236-8

17. R.H. Makasheva, Cultivated flora of the USSR (Kolos, Leningrad, 1979)

18. H. Lamprecht, Agr. Hort. Gen. 15, 142-154 (1957)

19. J.B. Reid, J.J. Ross, Genetics 189, 3-10 (2011) DOI: 10.1534/genetics.111.132118

20. P. Smýkal, G. Aubert, J. Burstin et al., Agronomy 2, 74-115 (2012) DOI: 10.3390/agronomy2020074 